\title{
- Avaliação das condições veterinárias e de manejo dos pequenos felinos neotropicais em cativeiro no Estado de São Paulo
}

\section{- Veterinary conditions and management evaluation of small brazilian cats in captivity in state of São Paulo}

\author{
Cristina Harumi Adania ${ }^{1}$ - CRMV-SP n ${ }^{0}$ 4531, Lilian de Stefani Munaó Diniz ${ }^{1,2}$ - \\ CRMV-SP $n^{0} 0843$, Marcelo Silva Gomes ${ }^{4}$ - CRMV-SP n ${ }^{0} 6266$, \\ Cláudia Filoni - CRMV-SP n ${ }^{0} 9287$ e Jean Carlos Ramos Silva ${ }^{1,3}$ - CRMV-SP n ${ }^{0} 7681$
}

1 - Associação Mata Ciliar
Av. Emilio Antonon s/n. Caixa
postal 2020 , CEP $13208-990$.
Jundiai- SP.
2 - Lab. de Doenças por
Bactérias e Fungos
VPS- FMVZ-USP.
3 - Lab. de Doenças
Parasitárias VPS- FMVZ-USP.
4 - Parque Estoril São
Bernardo do Campo.
5 - Depto. Patologia -
FMVZ - USP.

1 - Associação Mata Ciliar Av. Emilio Antonon s/n. Caixa Jundiai- SP. 2 - Lab. de Doenças por Bactérias e Fungos VPS- FMVZ-USP. 3 - Lab. de Doenças Parasitarias VPS- FMVZ-USP. Parque Estoril São FMVZ - USP.

\section{RESUMO}

Espécies e subespécies de felinos brasileiros de pequeno porte estão ameaçadas de extinção e existem poucas informações biológicas e veterinárias a respeito desses animais. A Associação Mata Ciliar (AMC) se propôs a efetuar estudos visando ampliar os conhecimentos e contribuir para conservação de pequenos felinos neotropicais. Participaram 22 zoológicos, 113 animais foram cadastrados e 93 foram identificados (tatuagem e marcação eletrônica), classificados zoológicamente e manejados: Herpailurus yagouaroundi-gato mourisco $(16,6,0)$, Leopardus pardalis- jaguatirica $(18,15,0)$, Leopardus wiedii- gato maracajá $(3,4,0)$, Leopardus tigrinus- gato-do-mato-pequeno $(21,10,0)$. Os resultados obtidos através da avaliação clínica e de aspéctos envolvendo os animais, permitiram constatar que ao redor de $50 \%$ dos indivíduos apresentam alterações ligadas ao manejo sendo elas, podológicas, dermatológicas, odontológicas, além da condição física insatisfatória. Conclui-se que há necessidade de se melhorar o manejo, a qualidade dos recintos e de se reverter a baixa taxa de nascimento, bem como reduzir o alto índice de mortalidade dos recém nascidos. O plantel desses felinos em criadouros ou zoológicos constituem banco genético fundamental, tendo como meta possbilitar um plano de manejo futuro na natureza, visando assegurar a biodiversidade.

Unitermos: animais silvestres, doenças, Felidae, felinos neotropicais, manejo

\section{Introdução}

Nas últimas décadas vem se observando intenso processos de destruição dos ecossistemas naturais, fato este proveniente do descaso geral do homem moderno frente à natureza. Como conseqüência imediata e direta desse quadro, aponta-se a perda irreparável de parte da biodiversidade (WILDT et al., 199041), inclusive no Brasil (MORELLATO, 199229; EMMONS, 1990²1), berço de grande diversidade biológica.

Os animais carnivoros, especialmente os felinos, em função de seus hábitos alimentares ocupam os níveis mais elevados da teia alimentar, fato que aliado à necessidade de grandes extensões territoriais para seu suprimento alimentar, faz com que sejam os primeiros a sofrerem com as alterações dos seus habitates (BECKER, DALPONTE, 19912).

Na familia Felidae (Mammalia- Carnivora) existem ao redor de 37 espécies distribuídas por todo planeta, à exceção da Austrália, Nova Zelândia, Japão, Madagascar, certas ilhas da Australásia e do Caribe, e pólos. O porte físico é bastante variado e o peso está entre 2.0 $\mathrm{kg}$ para os pequenos felinos silvestres a $300 \mathrm{~kg}$, ou mais, para o tigre siberiano (NORWAK, 1991 ${ }^{30}$ ). Na América 
ADANIA, C. H.; DINIZ, L. S. M.; GOMES, M.S.; FILONI, C.; SILVA, J. C. R. Avaliação das condiçōes veterinárias e de manejo dos pequenos felinos neotropicais em cativeiro no Estado de São Paulo. Revista de Educação Continuada do CRMV-SP. São Paulo, fascículo 1, volume 1, p. 044 - 053 , 1998.

do Sul ocorrem 10 dessas espécies, ao redor de 1/3 das existentes no planeta, e no Brasil ocorrem 8, compreendendo grandes felinos: Panthera onca (onça pintada) Puma concolor (suçuarana ou puma ou onça parda); e pequenos felinos: Herpailurus yagouaroundi (gato mourisco ou jaguarundi), Leopardus pardalis (jaguatirica), Leopardus wiedii (gato-maracajá), Oncifelis geoffroyi (gato-do-mato-grande), Leopardus tigrinus (gato-do mato-pequeno) e Felis colocolo (gato-palheiro). Felis guigna (kod-kod) e Felis jacobita (gato-andino) habitam outros países sulamericanos (CABRERA, YEPES, $\left.1965^{4}\right)$.

Os felídeos são os mais bem adaptados quanto ao carnivorismo, possuindo grandes dentes carniceiros e limitado número de premolares e molares, possuindo a fórmula dentária I 3/3; C 1/1; PM 3/3-2; M 1/1. São predatórios caçando ampla variedade de animais e são propensos a viver solitariamente (DE LA FUENTE, 197913). Os grandes felinos arrancam pedaços de carnes com os dentes caninos que são engolidos inteiros, já os pequenos felinos usam seus molares mais extensivamente para mascar e moer o alimento antes de engolir. As unhas retráteis são características dos felinos, ficando recobertas por pele quando recolhidas. Uma característica anatômica que separa os gêneros é a morfologia da laringe. Membros do gênero Panthera vocalizam sob a forma de rugidos, por terem a ossificação incompleta do hióide- subfamília Pantherinae, enquanto que os indivíduos do gênero Leopardus, a protuberância óssea do hióide é substituída por banda cartilaginosa elástica- subfamília Felinae (NOWAK, 199130).

Dentre as diversas espécies que apresentam a sua população diminuída em decorrência das alterações do meio ambiente, estão as que formam o grupo dos "Pequenos Felinos Brasileiros". Com excessão do gato mourisco, todas as outras espécies se encontram na Lista Oficial de Espécies Ameaçadas de Extinção e fazem parte do "Red List of Threatned Animals" (THORNBACK, JENKINS, 1982 ${ }^{38}$; COIMBRA FILHO, 19727). A situação dessas espécies se agrava ainda mais em virtude da remoção da natureza, da caça predatória indiscriminada que ocorre em todo o território brasileiro, além da dificuldade de se conseguir sua reprodução e manutenção em cativeiro, constatando-se baixa taxa de nascimento e alta mortalidade dos recém nascidos (CENSO, 19955).

As espécies de pequenos felinos neotropicais estão entre as menos conhecidas do planeta, existindo poucos trabalhos relativos à sua biologia, destacando-se trabalho em vida livre (CISIN,19976; CRAWSHAW Jr, QUIGLEY, 198911; SCHALLER, 198335), comportamento (PETERSON, 1974¹), genética de pequenos fe- linos em cativeiro (SOUZA et al., 1998 ${ }^{37}$ ). Nota-se lacuna, ainda maior, quanto aos estudos relativos à medicina veterinária desses felinos (FOWLER, 199323; 198622; WALLACK, BOEVER, 198339; GRINER, $\left.1983^{24}\right)$.

Em virtude desses fatos, a Associação Mata Ciliar (AMC) propôs-se a efetuar estudos sobre os pequenos felinos neotropicais mantidos em cativeiro no estado de São Paulo, com o escopo de obter informações para montar Banco de Dados para as espécies em questão. As informações obtidas nas áreas de biologia e veterinária permitirão confeccionar protocolo para o plano de manejo integrado dos pequenos felinos brasileiros em cativeiro. Como objetivo do estudo dos pequenos felinos nacionais em cativeiro no Estado de São Paulo pretendese:

1 - Efetuar levantamento das instituições e dos felinos em cativeiro (número, espécies, sexo e procedência)

2 - Efetuar classificação zoológica e marcação dos indivíduos para devida identificação e controle médico veterinário

3 - Avaliar a qualidade dos recintos e das condições gerais oferecidas para reprodução

4 - Avaliar as condições sanitárias (medidas preventivas, problemas clínicos, exames clínicos laboratoriais)

5 - Coletar informações para servir de banco de dados para estudos futuros de pequenos felinos neotropicais em vida livre

\section{Material e métodos}

Foram percorrido os municípios do estado de São Paulo que mantém pequenos felinos neotropicais na coleção dentre zoológicos e criadouros efetuando-se uma a quatro visitas a cada entidade, perfazendo ao redor de 17 $000 \mathrm{~km}$. Formulários foram elaborados com a finalidade de se obter informação sobre os animais e as entidades, onde foram cadastrados junto ao Plano para Manejo de Pequenos Felinos Brasileiros 113 animais, tendo-se manejado e coletado dados de 93 indivíduos.

Para marcação (93 animais), foi utilizado o sistema de tatuagem, transcrevendo-se o número do animal correspondente ao "studbook", mediante o emprego de aparelho tatuador com agulha embebida em tinta vegetal. O sistema de marcação eletrônica (Trovan AEG Telefunken, Alemanha) foi empregado em 64 indivíduos para fins comparativos. Este método utiliza "microchip (transponder)", que se trata de peça em vidro do tamanho de um grão de arroz, a qual foi introduzida sob a 
ADANIA, C. H.; DINIZ, L. S. M.; GOMES, M.S.; FILONI, C.; SILVA, J. C. R. Avaliação das condições veterinárias e de manejo dos pequenos felinos neotropicais em cativeiro no Estado de São Paulo. Revista de Educação Continuada do CRMV-SP. São Paulo, fascículo 1, volume 1, p. 044 - 053 , 1998.

pele do animal por meio de um aplicador, e a decodificação do número foi realizada pelo aparelho leitor, aproximando-o da região do implante.

Para exames clínicos e realização de coletas de material para exames laboratoriais os animais foram contidos inicialmente com auxílio de puçá para, a seguir, receberem drogas para imobilização química por via intramuscular. Em alguns casos os animais foram imobilizados quimicamente por meio de zarabatana.

Drogas empregadas para imobilização química (DINIZ, 1974 ${ }^{14}$; DINIZ, 199516)

-Cloridrato de quetamina, $50 \mathrm{mg} / \mathrm{ml}(10-12 \mathrm{mg} / \mathrm{kg})^{\mathrm{a}}$ -Cloridrato de xilazina, $20 \mathrm{mg} / \mathrm{ml}(1-2 \mathrm{mg} / \mathrm{kg})^{\mathrm{b}}$

A avaliação da qualidade dos recintos foi baseada em: avaliação da construção (material empregado, tipo, dimensões, cambiamento para separação ou isolamento dos indivíduos), distância do público, grau de insolação, tipo de ambientação (presença de troncos, vegetação, tipo de substrato, etc.), densidade ocupacional, tipo de co- chos para comida e água. Estes itens foram avaliados tendo como padrão as necessidades básicas para os pequenos felinos, recebendo as seguintes pontuações: $1=$ atendeu $20 \%$ das exigências, $2=$ atendeu entre 20 a 50 $\%, 3=$ atendeu $50 \%, 4=$ atendeu todos os requisitos $\mathrm{e}$ $5=$ qualidade superior aos requisitos básicos.

\section{Resultados e discussão}

Dentre os 41 zoológico do Estado de São Paulo, averiguou-se que 23 instituições mantém pequenos felinos neotropicais em cativeiro. Na tabela 1 estão as entidades que colaboraram no estudo, bem como o número de animais, sexos e as espécies mantidas nas respectivas coleções.

Os animais foram classificados zoologicamente, constatando-se que muitos indivíduos estavam erroneamente identificados, devido semelhança de suas características de pelagem e porte (RODRIGUES, AURICHIO,

Tabela 1 - Espécies*1, número e sexo de pequenos felinos neotropicais em cativeiro e entidades participantes do Estado de São Paulo.

\begin{tabular}{|c|c|c|c|c|}
\hline ENTIDADES E NÚMERO DE VISITAS & H. yagouaroundi & L. pardalis & L. tigrinus & L. wiedit \\
\hline Associação Mata Ciliar (Jundiai)*2 & $2(1,1,0)$ & - & $2(1,1,0)$ & $2(0,2,0)$ \\
\hline Bosque dos Jequitibás (Campinas) - 5 & $1(1,0,0) \star 3$ & $2(1,1,0)$ & $4(4,0,0)$ & $1(1,0,0)$ \\
\hline Bosque Municipal de Pedreira (Pedreira) - 4 & $2(1,1,0)$ & $1(0,1,0)$ & $2(1,1,0)$ & $\cdot$ \\
\hline Centro de Ed. Ambiental Francisco Mendes (Mogi Guaçu) - 3 & - & $2(1,1,0)-$ & $1(0,1,0)$ & - \\
\hline Criadouro Núcleo Faunistico Abrahão Zarzur (Ibaté)- 1 & - & $2(1,1,0)$ & $\cdot$ & $\cdot$ \\
\hline Criadouro Rancho das Hortências (Tapirai) - 2 & - & $\cdot$ & $\cdot$ & $2(1,1,0)$ \\
\hline Parque Ecológico Dr. Antonio T. Viana (São Carlos)- 2 & - & $2(0,2,0)$ & $3(1,2,0)$ & - \\
\hline Parque Ecológico Mourão (Leme) -1 & - & $1(1,0,0)$ & $2(2,0,0)$ & - \\
\hline Parque das Hortências (Taboão da Serra) - 2 & - & $2(1,1,0)$ & - & - \\
\hline Parque Min. Antonio de Pádua Nunes (S. José do Rio Pardo) - 2 & $3(3,0,0)$ & $1(0,1,0)$ & $3(2,1,0)$ & - \\
\hline Parque Zoológico de llha Solteira (llha Solteira) - 1 & $\cdot$ & $1(1,0,0)$ & - & $\cdot$ \\
\hline Parque Zoológico Mun. Quinzinho de Barros (Sorocaba) - 1 & $5(4,1,0)$ & $\cdot$ & $2(2,0,0)$ & $2(1,1,0)$ \\
\hline Parque Zoológico Municipal de Bauru (Bauru) - 3 & $3(2,1,0)$ & $2(1,1,0)$ & $2(1,1,0)$ & $\cdot$ \\
\hline Zoológico Municipal de Catanduva (Catanduva) - 3 & $1(1,0,0)$ & $\cdot$ & $1(1,0,0)-$ & - \\
\hline Zoológico Municipal Dr. Flávio Leite Ribeiro (Araçatuba) - 3 & - & $1(1,0,0)$ & $2(2,0,0)$ & - \\
\hline Zoológico Municipal de Garça (Garça) - 3 & $1(0,1,0)$ & $2(1,1,0)$ & & - \\
\hline Zoológico Municipal de Guarulhos (Guarulhos) - & - & $3(2,1,0)$ & - & - \\
\hline Zoológico Municipal de Limeira (Limeira) - 1 & - & $1(1,0,0)$ & $1(1,0,0)$ & - \\
\hline Zoológico Municipal Luiz Gonzaga A. Campos (Mogi Mirim) - 4 & $2(1,1,0)$ & $2(1,1,0)$ & - & - \\
\hline Zoológico Municipal de Piracicaba (Piracicaba) - 3 & - & $2(1,1,0)-$ & $2(1,1,0)$ & - \\
\hline Zoológico Municipal de S. José do Rio Preto (S. José do Rio Preto) - 3 & $2(2,0,0)$ & $4(3,1,0)$ & $2(1,1,0)$ & - \\
\hline Zoológico Parque Francisco Mendes (S. Bernardo do Campo) - 3 & & $2(1,1,0)$ & $2(1,1,0)$ & $\cdot$ \\
\hline TOTAL DE ENTIDADES $=22$ & $22(16,6,0)$ & $33(18,15)$ & $31(21,10)$ & $7(3,4,0)$ \\
\hline TOTAL DE ANIMAIS MANEJADOS $=93$ & & & & \\
\hline
\end{tabular}

${ }^{*}$ H. yagouaroundi (gato mourisco), L. pardalis (jaguatirica), L. tigrinus (gato-do-mato-pequeno) e L. wiedii (gato maracajá)

*2 Sede da Entidade - Associação Mata Ciliar, que coordenou a pesquisa

*3Total (machos, fêmeas, não determinado) 
ADANIA, C. H.; DINIZ, L. S. M.; GOMES, M.S.; FILONI, C.; SILVA, J. C. R. Avaliação das condiçōes veterinárias e de manejo dos pequenos felinos neotropicais em cativeiro no Estado de São Paulo. Revista de Educação Continuada do CRMV-SP. São Paulo, fascículo 1, volume 1, p. 044 - 053 , 1998.

199434). Nas instituições paulistas que fizeram parte do estudo, observou-se a presença de quatro espécies de pequenos felinos neotropicais em cativeiro no Estado de São Paulo, a saber: Leopardus tigrinus (gato-do-matopequeno), Leopardus wiedii (gato maracajá), Herpailurus yagouaroundi (gato mourisco) e Leopardus pardalis (jaguatirica). Nas figuras de 1 a 5 estão cinco das seis espécies de pequenos felinos neotropicais distribuídas pelo território nacional.

Os animais estudados procederam principalmente da natureza $(90 \%)$, tendo sido recebidos pelos zoológicos mediante doação por particulares, ou foram deixados após apreensão oficial pela Polícia Florestal, Corpo de Bombeiros ou Guarda Municipal, etc.

Com relação à identificação dos animais através de tatuagem, este sistema mostrou tratar-se de método econômico, de fácil aplicação, salientando que a clareza

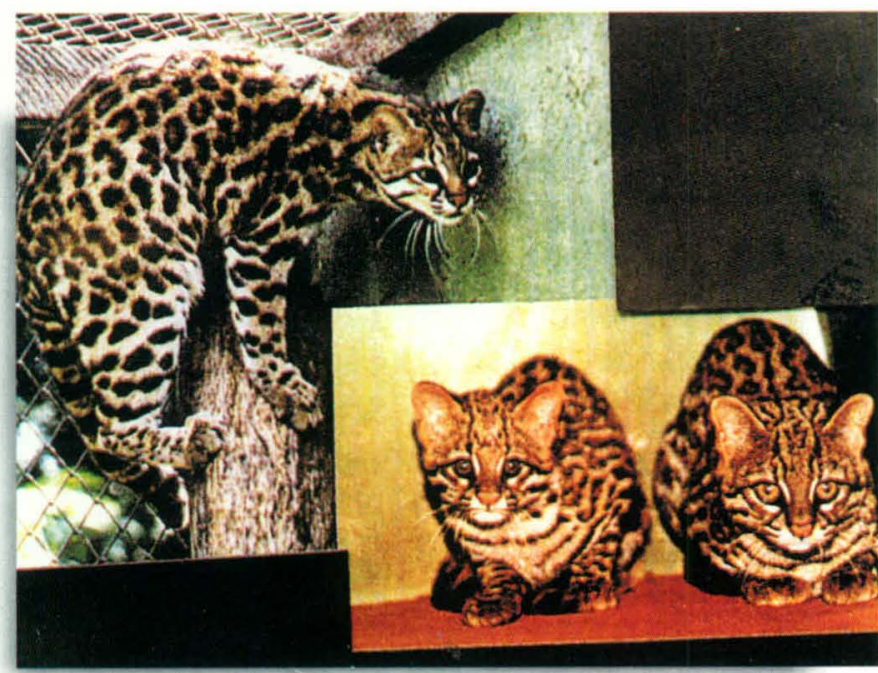

Figura 1 - Leopardus tigrinus, gato-do-mato-pequeno

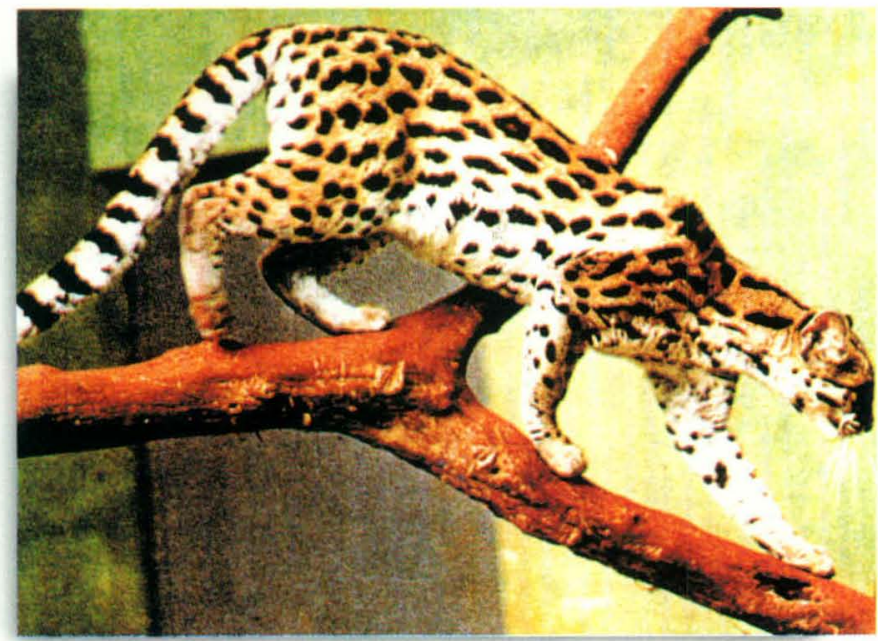

Figura 2- Leopardus wiedii, gato maracajá

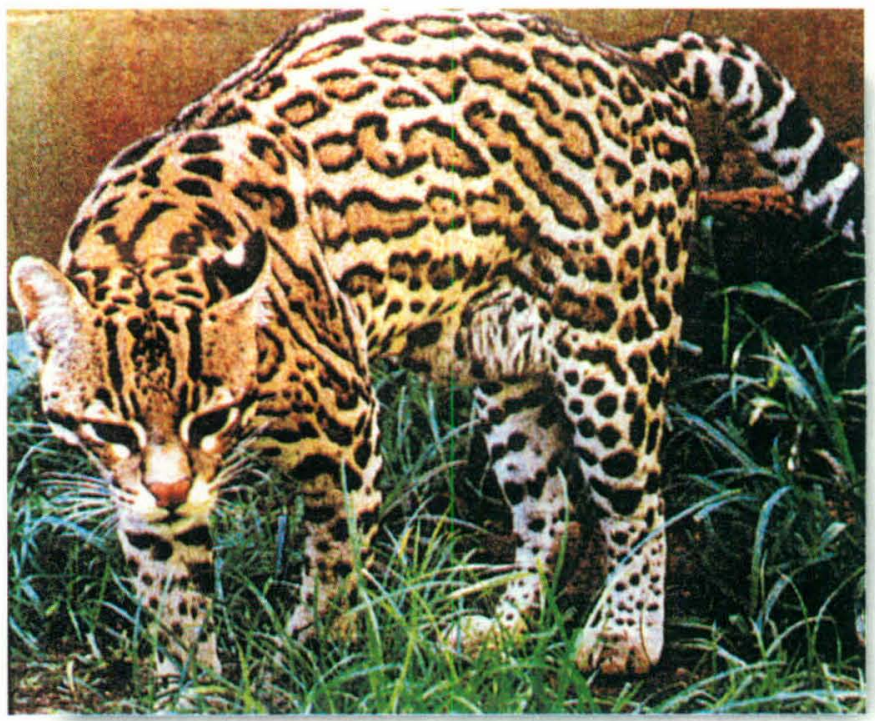

Figura 3 - Leopardus pardalis, jaguatirica

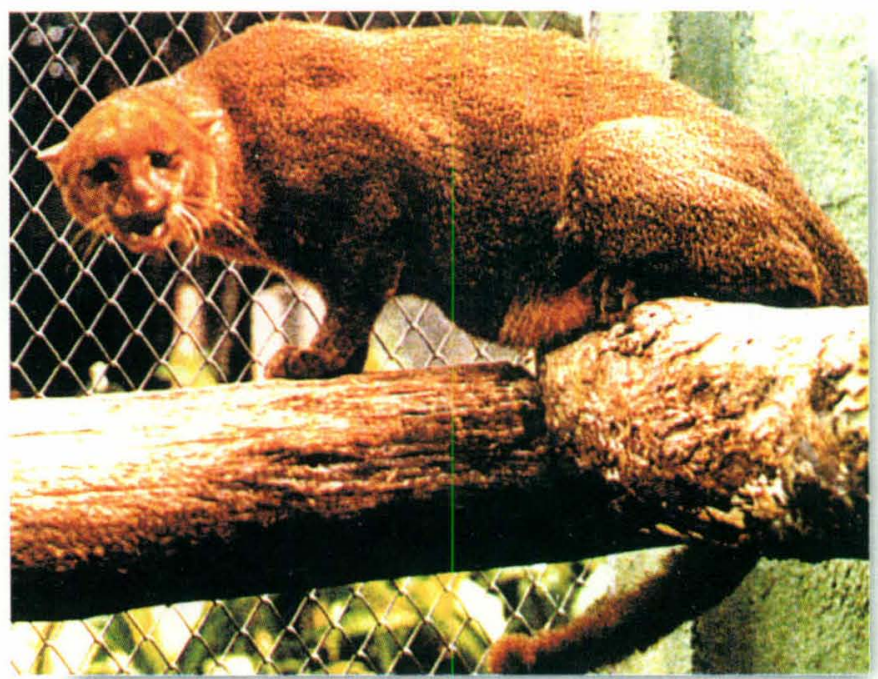

Figura 4 - Herpailurus yagouaroundi, gato mourisco

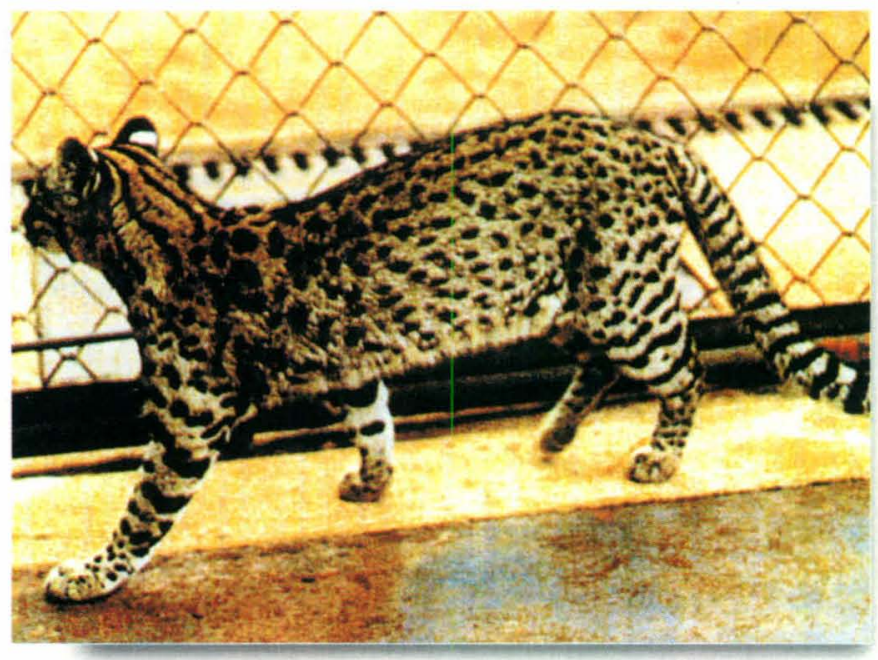

Figura 5 - Oncifelis geoffroyi, gato-do-mato-grande 
ADANIA, C. H.; DINIZ, L. S. M.; GOMES, M.S.; FILONI, C.; SILVA, J. C. R. Avaliação das condições veterinárias e de manejo dos pequenos felinos neotropicais em cativeiro no Estado de São Paulo. Revista de Educação Continuada do CRMV-SP. São Paulo, fascículo 1, volume 1, p. 044 - $053,1998$.

para se ler os números esteve na dependência da habilidade do operador em tatuar. Nos 64 felinos que receberam a marcação eletrônica esta mostrou-se bastante precisa, de fácil aplicação, duração permanente, porém onerosa em virtude da necessidade de reposição e do equipamento ser importado.

$\mathrm{A}$ avaliação dos recintos quanto à qualidade $\mathrm{e}$ ambientação estão resumidos nas figuras 6 e 7 . O tipo de substrato do recinto exerceu possível influência sobre a ocorrência de alterações podais, dado ter se notado casos de abrasão nos coxins, além de poder promover lesões digestivas caso o alimento fosse colocado no solo forrado por areia ou saibro. O substrato da cama se confeccionado de feno grosseiro pode também promover graves alterações digestivas, conforme foi observado anteriormente em gato mourisco apresentando corpo estranho no estômago, formado por massa vegetal compacta ocupando todo compartimento, levando o animal à morte.
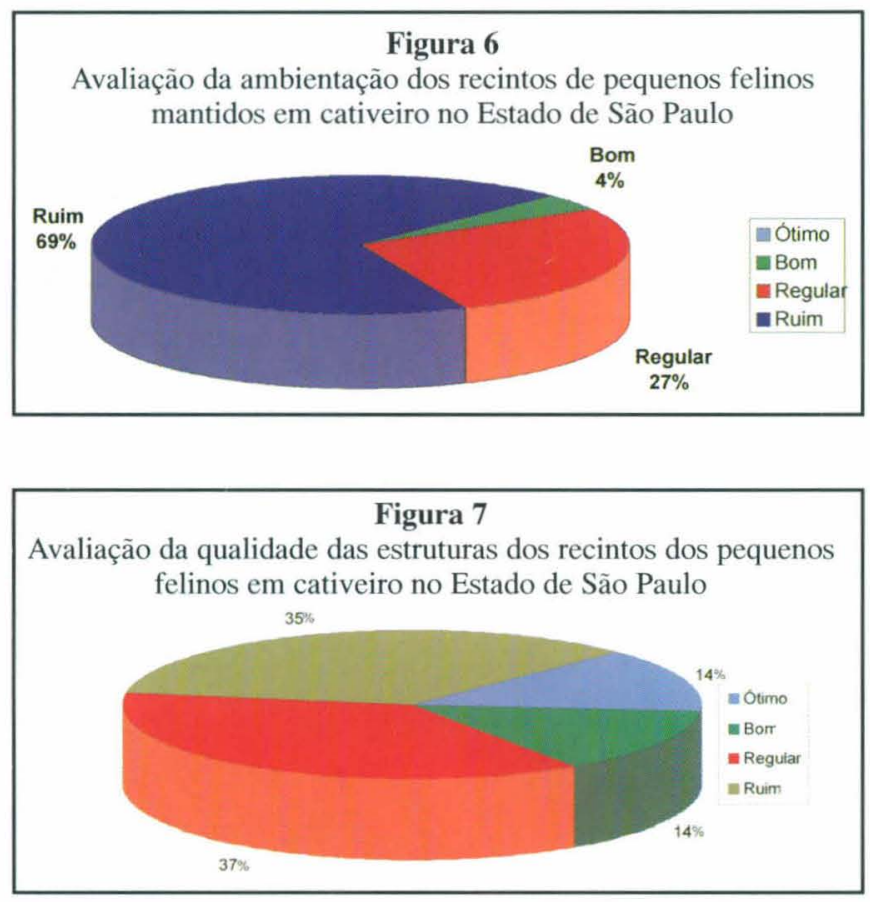

Constatou-se que os pequenos felinos em cativeiro no Estado de São Paulo apresentam baixo grau de pareamento (tabela 2), ou seja, muitos estão isolados ou constituem grupos de indivíduos de mesmo sexo, se tornando grave impecílio para reprodução. Os pequenos felinos possuem baixo índice de natalidade nos zoos, salientando-se o levantamento retrospectivo de cinco anos efetuado anteriormente apontando o registro de apenas 01 nascimento com sucesso dentre quatorze gatos-domato-pequenos (WILDHOZER et al., 198140).
Tabela 2 - Situação de pareamentos dos pequenos felinos em cativeiro no Estado de São Paulo.

\begin{tabular}{|l|c|c|c|c|}
\hline Animais & H. yagouaroundi & L. pardalis & L. tigrinus & L. wiedii \\
\hline Animais pareados & 10 & 20 & 12 & 02 \\
\hline Machos disponiveis & 11 & 08 & 15 & 02 \\
Femeas disponiveis & 01 & 05 & 04 & 03 \\
\hline
\end{tabular}

${ }^{* 1}$ H. yagouaroundi (gato mourisco), L. pardalis (jaguatirica), L. tigrinus (gato-do-mato-pequeno) e L. wiedii (gato maracajá)

Os aspectos veterinários foram avaliados, primeiramente, quanto às medidas preventivas. A área destinada ao quarentenário em zoológicos na verdade constituíse no chamado "setor extra", ou seja, local onde os animais em quarentena permanecem alojados em recintos contíguos aos animais excedentes aguardando destinação. Deparou-se que tal situação chega a levar até alguns anos, devido imensa dificuldade de se destinar esses excedentes. Tal proximidade entre os animais pode conduzir facilmente ao desenvolvimento de surto de moléstias parasitárias e/ou infecciosas, inter e intra espécies de carnívoros. Neste particular, menciona-se a ocorrência de surto de parvovirose que acometeu 17 lobos guarás (DINIZ et al. 198917; DINIZ et al., 199619). O levantamento epidemiológico efetuado para se apurar a origem do processo, apontou a possibilidade do envolvimento de uma onça e duas jaguatiricas jovens em período de quarentena, apresentando hemograma e sinais clínicos compatíveis com esta virose, tendo sido isoladas desses felinos, particulas semelhantes ao parvovirus canino (ÂNGELO et al., 19881).

Os pequenos felinos que fizeram parte do presente estudo encontravam-se sem imunização (vacina de vírus inativado) contra as principais viroses felina. O programa de vacinação foi posto em ação graças à importação conseguida especialmente pela AMC, onde os animais receberam as vacinas (tabela 3), contra panleucopenia felina, rinotraqueíte e calicivirose $\mathrm{e}^{\mathrm{c}}$ e raiva.

Tabela 3 - Esquema adotado para aplicação da vacina tríplice felina, panleucopenia, rinotraqueíte e calicivírus, para pequenos felinos neotropicais em cativeiro.

\begin{tabular}{|l|c|c|c|c|}
\hline & 1a dose & Reforço 1 & Reforço 2 & $\begin{array}{c}\text { Demais } \\
\text { reforços }\end{array}$ \\
\hline Filhotes & $\begin{array}{c}60 \text { dias } \\
\text { de idade }\end{array}$ & $\begin{array}{c}75 \text { dias } \\
\text { de idade }\end{array}$ & $\begin{array}{c}90 \text { dias de } \\
\text { idade }\end{array}$ & anual \\
\hline $\begin{array}{l}\text { Adultos sem } \\
\text { vacinação }\end{array}$ & quarentena & $\begin{array}{c}\text { após } 30 \text { dias } \\
\text { da } 1^{\mathrm{a}} \text { dose }\end{array}$ & $\begin{array}{c}\text { após } 60 \text { dias } \\
\text { da } 1^{\mathrm{a}} \text { dose }\end{array}$ & anual \\
\hline
\end{tabular}


ADANIA, C. H.; DINIZ, L. S. M.; GOMES, M.S.; FILONI, C.; SILVA, J. C. R. Avaliação das condições veterinárias e de manejo dos pequenos felinos neotropicais em cativeiro no Estado de São Paulo. Revista de Educação Continuada do CRMV-SP. São Paulo, fascículo 1, volume 1, p. 044 - 053 , 1998.

Quanto aos processos orgânicos, observou-se alterações notadamente em conseqüência de problemas de manejo (fig. 8). Os processos dentários corresponderam às gengivites e periodontites devido litíase dentária (Fig. 9), que pode ocorrer em conseqüência de textura inadequada dos alimentos fornecidos. Foram constatadas, também, fraturas em decorrência de traumatismos sobre coroas de dentes caninos, seguindo-se pulpites (infecção do feixe vásculo-nervoso) e acúmulo de tecido necrosado no canal dentário. Alterações das unhas foram representadas por desgaste acentuado ou crescimento excessivo chegando, neste último caso, a ferir o coxim, sabendo-se que tais alterações surgem pela ausência de elementos para o felino efetuar o devido desgaste. Erosão dos coxins plantares e palmares foram outras alterações podológicas encontradas, advindo em conseqüência de piso abrasivo. Os processos dermatológicos foram representados notadamente por alopecia e/ou rarefação dos pêlos, os quais tiveram causas variáveis, como a presença de ectoparasitas e causas comportamentais (lambeduras intensas) e nutricionais. O gato-do-mato-pequeno ( $L$. tigrinus) e gato mourisco (H. yagouaroundi) apresenta-

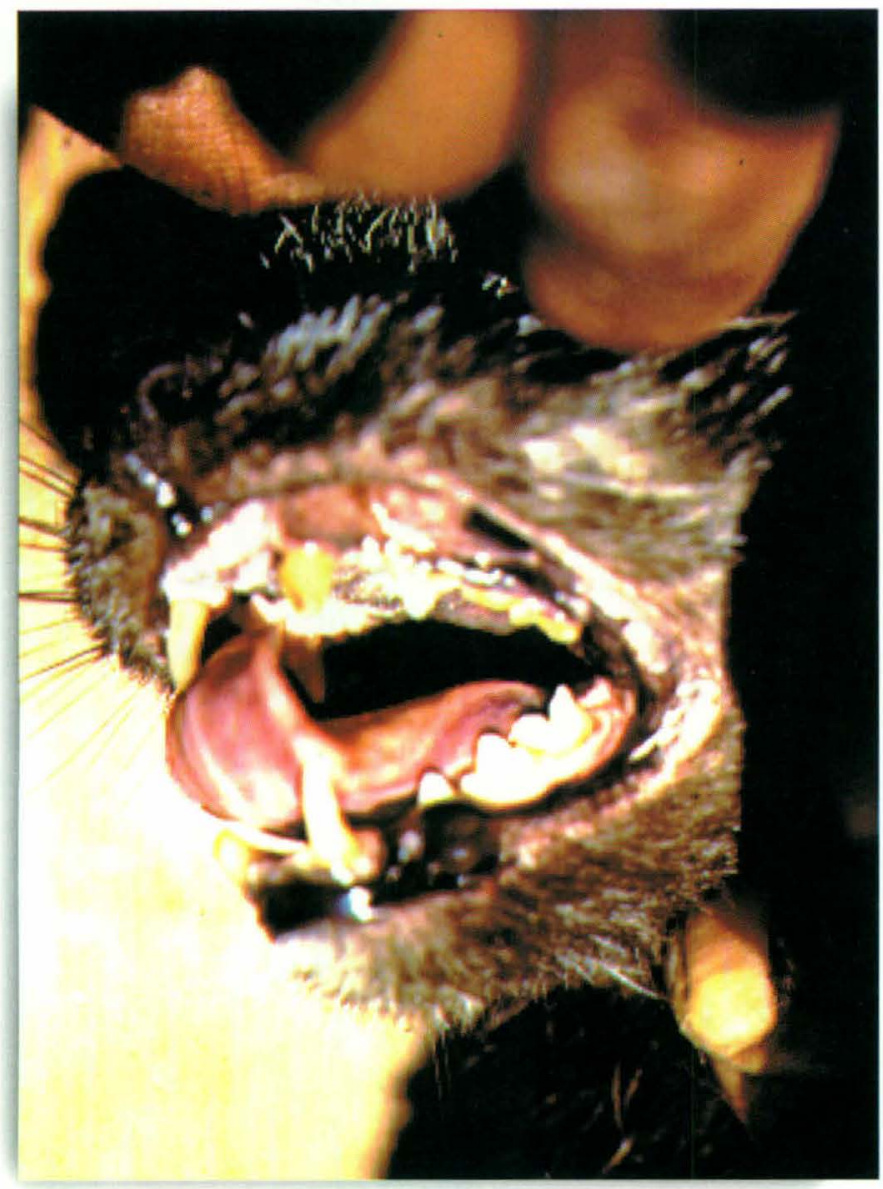

Figura 9 - Litiase dental em gato mourisco

\section{Figura 8}

Valores percentuais dos diferentes processos clínicos em felinos neotropicais em cativeiro no Estado de São Paulo

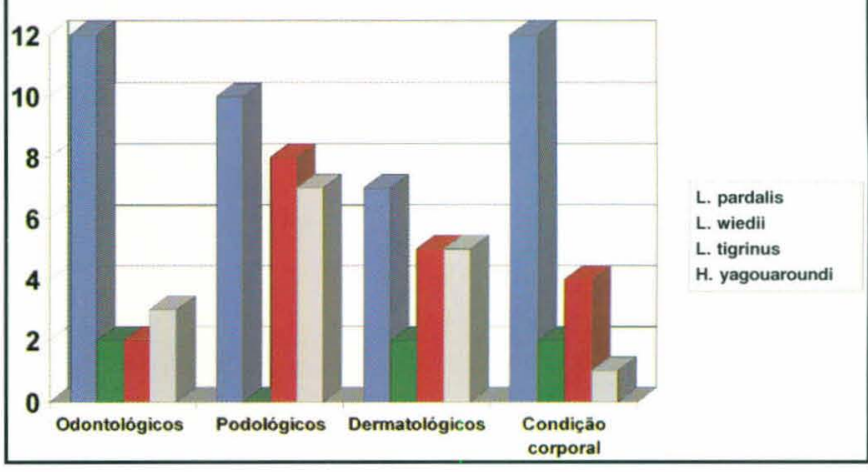

ram cerca de $30 \%$ de ectoparasitose por pulgas (Ctenocephalides sp). Aponta-se altíssima infestação nesses felinos em cativeiro, tendo sido constatado centenas delas por indivíduo (fig. 10), causando processo anêmico acentuado como resultado de intensa ação hematófaga deste ectoparasita. O combate foi efetuado mediante tratamento mensal, repetido três vezes, aplicando-se fipronil tópi$\mathrm{co}^{\mathrm{d}}$, complementado por ação de vassoura de fogo nos recintos e camas. Como agente de processo dermatológico, cita-se caso de sarna por Sarcoptes scabei em gatodo-mato-pequeno, promovendo alteração anatômica dos pavilhões auriculares (DINIZ et al., 199718).

O manejo alimentar dos pequenos felinos em cativeiro mostrou-se deficiente, onde a avaliação da condição física apontou alta incidência de animais magros e

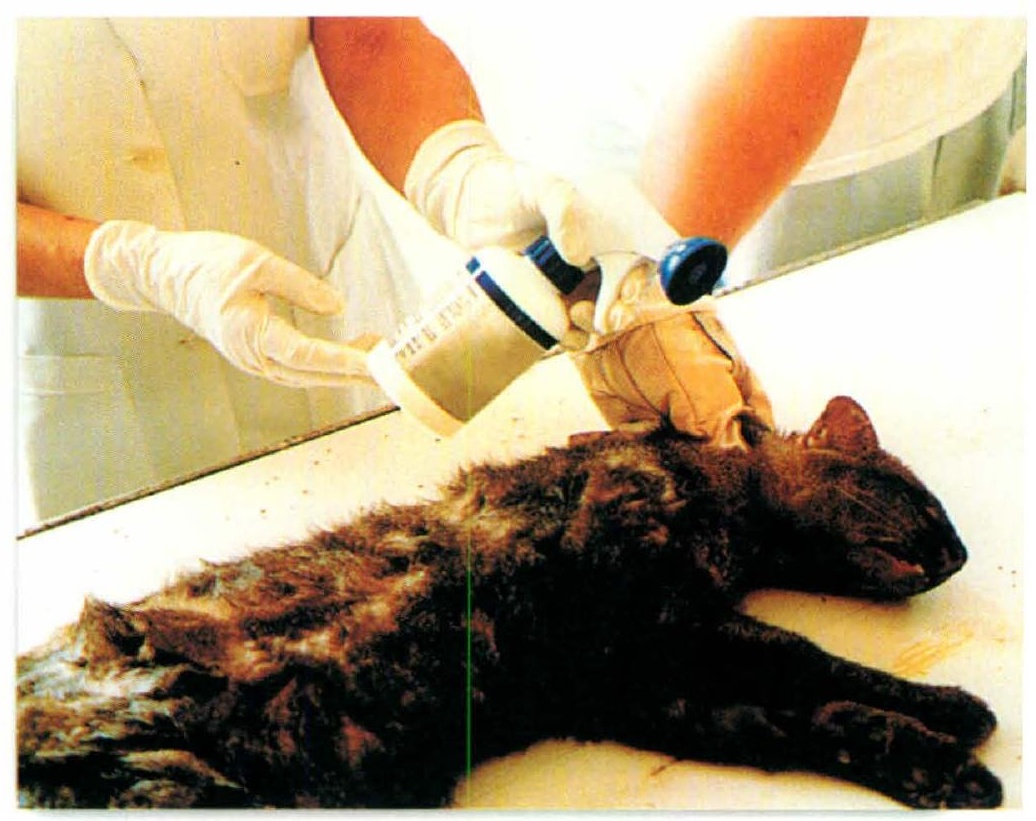

Figura 10 - Infestação maciça por pulgas- Ctenocephalides sp em gato mourisco 
ADANIA, C. H.; DINIZ, L. S. M.; GOMES, M.S.; FILONI, C.; SILVA, J. C. R. Avaliação das condições veterinárias e de manejo dos pequenos felinos neotropicais em cativeiro no Estado de São Paulo. Revista de Educação Continuada do CRMV-SP. São Paulo, fascículo 1, volume 1, p. 044 - $053,1998$.

Tabela 4 - Valores médios de proteína sérica total e de suas frações $(\mathrm{g} / \mathrm{ml})$ em diferentes espécies de felinos em cativeiro.

\begin{tabular}{|c|c|c|c|c|c|}
\hline & \multirow{2}{*}{$\begin{array}{l}\text { Proteina total } \\
\qquad(\mathrm{g} / \mathrm{ml})\end{array}$} & \multicolumn{4}{|c|}{ Frações $(\mathrm{mg} / \mathrm{ml})$} \\
\hline & & Albumina & Alfa & Beta & Gama \\
\hline $\begin{array}{l}\text { L. tigrinus } \\
(10)\end{array}$ & $\begin{array}{c}7,93 \\
\text { C. } V^{* 2}=0,147\end{array}$ & $\begin{array}{c}X^{* 2}=3,067 \\
\text { D.P } P^{* 2}=0,450 \\
0,301\end{array}$ & $\begin{array}{l}0,879 \\
0,265 \\
0,219\end{array}$ & $\begin{array}{l}1,870 \\
0,409 \\
0,187\end{array}$ & $\begin{array}{l}2,131 \\
0,398\end{array}$ \\
\hline $\begin{array}{l}\text { L. wiedii } \\
\text { (10) }\end{array}$ & $\begin{array}{c}7,93 \\
\text { C.V. }=0,147\end{array}$ & $\begin{array}{c}X=3,067 \\
\text { D.P. }=0,450 \\
0,301\end{array}$ & $\begin{array}{l}0,879 \\
0,265 \\
0,219\end{array}$ & $\begin{array}{l}1,870 \\
0,409 \\
0,187\end{array}$ & $\begin{array}{l}2,131 \\
0,398\end{array}$ \\
\hline $\begin{array}{l}\text { L. pardalis } \\
\text { (15) }\end{array}$ & $\begin{array}{c}10,29 \\
\text { C.V. }=0,167\end{array}$ & $\begin{array}{c}X=3,377 \\
\text { D.P. }=0,677 \\
0,319\end{array}$ & $\begin{array}{l}1,226 \\
0,392 \\
0,131\end{array}$ & $\begin{array}{l}2,317 \\
0,303 \\
0,210\end{array}$ & $\begin{array}{l}2,684 \\
0,563\end{array}$ \\
\hline $\begin{array}{l}\text { P. onca } \text { on }^{* 1} \\
\text { (18) }\end{array}$ & $\begin{array}{c}8,96 \\
\text { C.V. }=0,312\end{array}$ & $\begin{array}{c}X=3,276 \\
\text { D.P. }=1,024 \\
0,359\end{array}$ & $\begin{array}{l}1,086 \\
0,390 \\
0,320\end{array}$ & $\begin{array}{l}1,953 \\
0,625 \\
0,376\end{array}$ & $\begin{array}{l}2,303 \\
0,867\end{array}$ \\
\hline $\begin{array}{l}\text { P. } l e o^{* 1} \\
(30)\end{array}$ & $\begin{array}{c}9,75 \\
\text { C.V. }=0,273\end{array}$ & $\begin{array}{c}X=4,048 \\
\text { D.P. }=0,921 \\
0,316\end{array}$ & $\begin{array}{l}1,130 \\
0,357 \\
0,282\end{array}$ & $\begin{array}{l}2,497 \\
0,703 \\
0,256\end{array}$ & $\begin{array}{l}2,872 \\
0,736\end{array}$ \\
\hline
\end{tabular}

* 1 Onça e leão respectivamente. Espécies estudadas para fins comparativos com os pequenos felinos neotropicais.

* $2 \mathrm{X}=$ média, D.P. = desvio padrão, C.V. = coeficiente de variação

outro tanto de obesos. Enquanto que 21,0\% dos gatosdo-mato-pequenos apresentaram baixo peso corporal, as jaguatiricas $(29,2 \%)$ apresentaram obesidade em decorrência do volume alimentar, associado aos recintos pequenos e à pouca atividade. A alimentação tem grande influência sobre os valores fisiológicos e, neste particular, ressalta-se estudo sobre as proteínas séricas total e fracionadas (tabela 4), realizado anteriormente em felinos neotropicais (DINIZ, 197915).

Em pesquisa para avaliar a presença de anticorpos anti-Toxoplasma gondii, averiguou-se $49 \%$ de soropositivos dentre os felinos em cativeiro no Estado de São Paulo (SILVA, 1998 ${ }^{36}$ ). O estudo sobre a incidência de infecções bacterianas e por micoses profundas em mamíferos da fauna indígena em cativeiro foi realizado anteriormente, mediante aplicação de testes intradérmicos

Tabela 5 - Testes intradérmicos com antígenos bacterianos e fúngicos em pequenos felinos neotropicais $8,9,10,20$

\begin{tabular}{|l|c|}
\hline Antígenos & Felinos $^{*}(\mathbf{n = 1 2})$ \\
\hline Paracoccidioidina & $8,2 \%$ \\
\hline Histoplasmina & $10,2 \%$ \\
\hline Sporotrichina & $6,1 \%$ \\
\hline Nocardina & $12,2 \%$ \\
\hline Tuberculina & $2,2 \%$ \\
\hline
\end{tabular}

(COSTA et al. 19978; 19959; 199410; DINIZ et al., $1994^{20}$ ), estando os resultados referentes aos pequenos felinos compilados na tabela 5. Menciona-se a possibilidade de ocorrência de processo respiratório, notadamente no período outono-inverno, conforme foi constatado em caso agudo de pneumonia purulenta, precedido por apatia e inapetência, em gato mourisco estando três meses em cativeiro (BELLUOMINI et al. 1980-8133).

\section{Conclusões e considerações finais}

1 - Os aspectos clínicos para cada uma das espécies estudadas estão resumidos na fig. 11, onde pode-se observar a extrema necessidade de se melhorar as condições de manejo dos pequenos felinos em cativeiro no Estado de São Paulo, devido alta incidência dos processos orgânicos ligados ao manejo.

2 - A qualidade dos recintos, incluindo construção e ambientação, necessita passar por extensas alterações dado existirem alojamentos fora dos padrões estabelecidos (INSTRUÇÃO NORMATIVA, 199025) para as espécies em questão. (fig. 12).

3 - Há necessidade de se reverter a baixa taxa de nascimento promovendo, como primeiro passo, os devidos pareamentos dos individuos isolados; bem como 


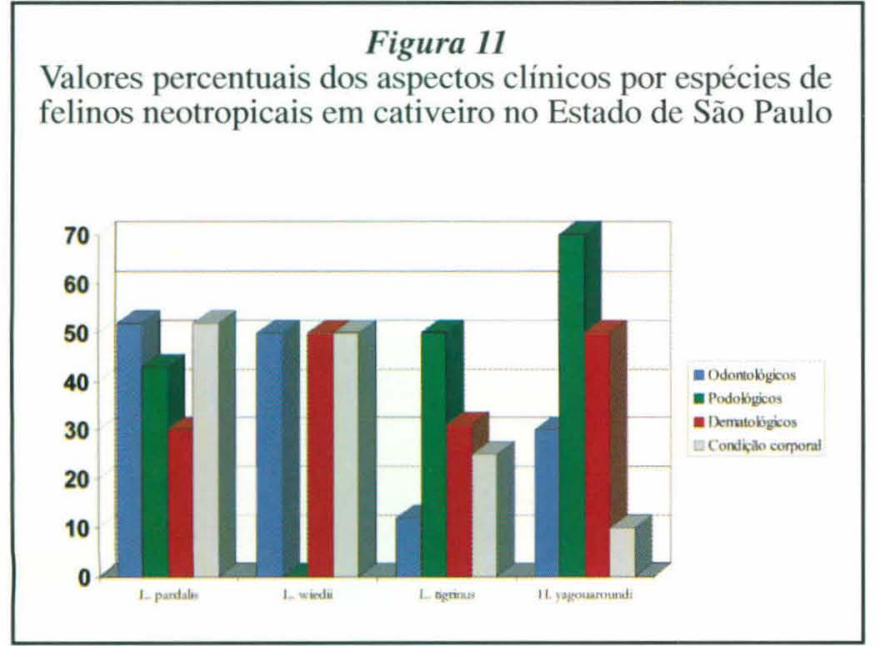

reduzir o alto índice de mortalidade dos recém nascidos.

A exemplo das publicações anteriores efetuadas pela Associação Mata Ciliar (MANEJO E CONSERVAÇÃO, 199327; PLANO DE MANEJO DA JAGUATIRICA, 199532; PROTOCOLO DE MANEJO INTEGRADO DA JAGUATIRICA, 199633), com os resultados obtidos até o momento será possível estabelecer o "Protocolo de Manejo para Pequenos Felinos Brasileiros", com a finalidade de esclarecer e informar à todos profissionais da área sobre as necessidades e exigências para o manejo adequado dos pequenos felinos neotropicais em cativeiro no Brasil.

Os resultados aqui apresentados constituem informações importantes de estudo inédito realizado no Brasil. Encerram conjunto de dados relevantes para contri-

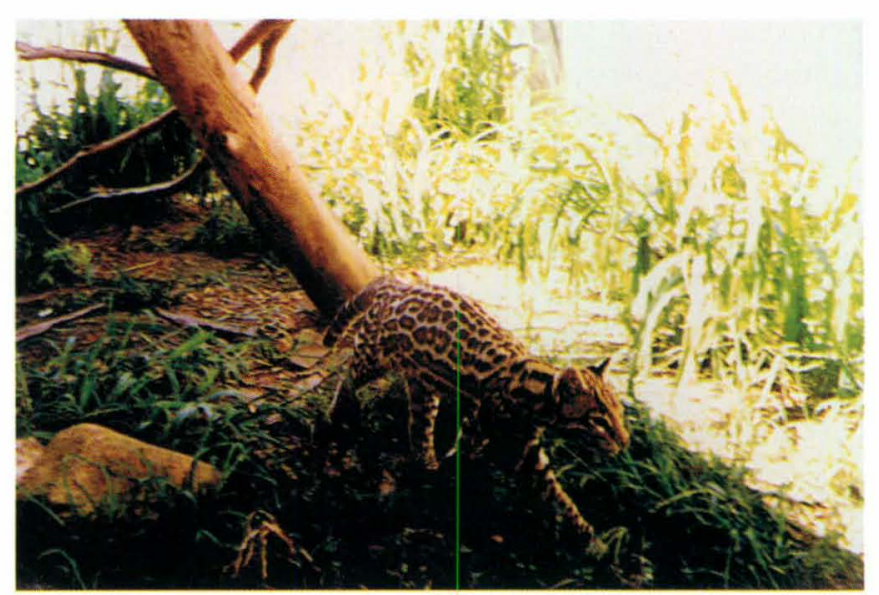

Figura 12 - Recinto adequado para pequenos felinos neotropicais. Associação Mata Ciliar, Jundiai/SP.

buir para a criação e manutenção dos pequenos felinos neotropicais em cativeiro. $\mathrm{O}$ plantel desses felinos em criadouros ou zoológicos constituem banco genético fundamental, tendo como meta a reintrodução criteriosa e cuidadosa na natureza (CUBAS, 199612; LUTZ et al. 199626; MIKOTA, AGUILAR, 199628), além deles servirem como padrão para estudos comparativos futuros de felinos em vida livre, visando assegurar a biodiversidade.

\footnotetext{
Associação Mata Ciliar - Coordenadoria de Fauna. Av. Emilio Antonon s/n. Caixa postal 2020, CEP 13208-990. Jundiai- SP.

${ }^{a}$ Ketamina 50. Holliday- Scott S.A. Int. Neyer 924 (1643) Beccar - Bs. As. Argentina.

${ }^{\mathrm{b}}$ Rompum. Bayer S.A. R. Domingos Jorge 1100, 04779-900. Socorro/SP.

c Vacina triplice felina- virus inativado. Fort Dodge.

${ }^{d}$ Frontline. Rhodia-Meriex Veterinária Ltda (Merial). R. Fernando Martini 28, 13073-060, V. Nova, Campinas/SP
}

\section{SUMMARY}

The species and subspecies of small Brazilian cats are in threatened with extinction and there is little biological and/or veterinary knowledge regarding these animals. The Associação Mata Ciliar (forest land association) has proposed a study with the idea of increasing the information and contributing to the preservation of these small sub-tropical cats. Twenty two zoos are taking part in this study, and 113 animals have been registered of which 93 animals were identified (electronic marking and tattooed), classified zoological and handled: Herpailurus yagouaroundiyaguarundi $(16,6,0)$, Leopardus pardalis- ocelot $(18,15,0)$, Leopardus wiedii- margay, long talled little-spoted cat $(3,4,0)$, Leopardus tigrinus- little-spoted cat $(21,10,0)$. The results obtained showed that approximately $50 \%$ of the felines presented clinical problems envolving management such as in the foot, tooth, skin problems and insatisfatory weight. It is possible to conclude that there is a significant need to improve the general management, the quality of enclosures, and the falling birth rate must be reverted, as well as reducing the alarming new birth mortality rate. The cat colonies held breeder and/or zoos provide a fundamental genetic bank from wich these cats can be returned to their natural habitat, as well as there serving as a standard for future comparative studies of these animals in their natural state, thereby assuring the bio-diversity maintenance.

Uniterms: disease, Felidae, New World feline, wild animals 


\section{REFERÊNCIAS BIBLIOGRÁFICAS}

1 - ÂNGELO, M.J.; DINIZ, L.S.M.; TANAKA, H.; FEDULLO, J.D.L. Ocorrência de enterite hemorrágica associada à parvovirose canina em felinos e canídeos silvestres do Zoo de São Paulo. In: ENCONTRO NACIONAL DE MICROBIOLOGIA AMBIENTAL, 2, Águas de Lindóia- SP, 1988. Anais.

2 - BECKER, M., DALPONTE, J.C. Rastos de mamiferos silvestres brasileiros; um guia de campo. Editora Universidade de Brasília, Brasília,1991.

3 - BELLUOMINI, H.E.; DINIZ L.S.M.; SALIBA, A.M. Finding of pathological anatomy in mammals from the Fundação Parque Zoológico de São Paulo in 1971. Memórias do Instituto Butantan, n.44/45, p.133-152, 1980-1981.

4 - CABRERA, A., YEPES, J. Mamiferos Sud Americanos. Vida, Costumbres y Descripcion. Compañia Argentina de Editores. Buenos Aires, 1965.

5 - CENSO de Animais Silvestres em Zoológicos no Brasil. (ed.). São Paulo. Sociedade de Zoológicos do Brasil. 1995.

6 - CISIN, C. Expecially ocelots. Harry G. Cisin, Amagansett, 1997.

7 - COIMBRA-FILHO, A.E. Mamíferos ameaçados de extinção. In: ACADEMIA BRASILEIRA DE CIÊNCIAS. Espécies da fauna brasileira ameaçadas de extinção. Rio de Janeiro, 1972.

8 - COSTA, E.O., DINIZ, L.S.M., FAVA NETTO. Ecological aspects of fungal and bacterial infections of wild mammals in South America. Israel Journal of Veterinary Medicine, v.52, n.4, p.137-140, 1997.

9 - COSTA, E.O.; DINIZ, L.S.M.; FAVA NETTO, C.; ARRUDA, C.; DADLI, M.L.Z. Delayed hypersensitivity test with paracoccidioidin in captive Latin American wild mammals. Journal of Medical and Veterinary Mycology, n.33, p.39-42, 1995.

10 - COSTA, E.O.; DINIZ, L.S.M.; FAVA NETTO, C.; ARRUDA, C.; DAGLI, M.L.Z.. Epidemiological study of Sporotrichosis and Histoplasmosis in Latin American wild mammals. Mycopathologia, n.125, p.19-22, 1994.

11 - CRAWSHAW Jr, P.G., QUIGLEY, H.B.. Notes on ocelot movemente and activity in the Pantanal Region, Brazil. Biotropica v.21, n.4, p.377-9. 1989.

12 - CUBAS, Z.S. Special challenges of maintaining wild animals in captivity in South America. Revue Scientifique et Technique- Office International des Épizooties, v.15, n.1, p.26787, 1996.

13 - DE LA FUENTE, F.R. A fauna- Vida e costumes dos animais selvagens. Rio de Janeiro, Salvat. 1979 vol.1 p. 210-239; vol.8 p. 201-212.

14 - DINIZ, L.S.M. Anestesia em animais silvestres. In: CONGRESSO BRASILEIRO DE MEDICINA VETERINÁRIA, 14, São Paulo, 1974. Anais, p.333-334.
15 - DINIZ, L.S.M., Proteínas séricas total e fracionada em algumas espécies de felinos silvestres. São Paulo, Universidade de São Paulo- SP, 1979. Tese doutoramento. Instituto de Biociências da USP.

16 - DINIZ, L.S.M. Imobilização química dos animais silvestres, In: Spinosa, H.S et alii. Farmacologia aplicada à medicina Veterinária, $1^{\mathrm{a}}$ edicão, Rio de Janeiro, Guanabara Koogan, 1994. p.153-63.

17 - DINIZ, L.S.M.; ÂNGELO, M.J.; FEDULLO; J.D.L. Surto de parvovirose em canídeo Chrysocyon brachyurus (Illiger, 1811) lobo guará em cativeiro. In: Congresso Paulista de Medicina Veterinária, São Paulo- SP, 1989. Anais, p. 29.

18 - DINIZ, L.S.M.; COSTA, E.O.; BENITES, N.R. Processos dermatológicos dos animais silvestres. Clínica Veterinária, v.2, n.8, p.6-9, 1997.

19 - DINIZ, L.S.M.; LAZZARINI, M.S.; COSTA, E.O.; ÂNGELO M.J. Lobo guará: principais moléstias em cativeiro. In: CONGRESSO PANAMERICANO DE CIÊNCIAS VETERINÁRIAS, 25, Campo Grande, MS, 1996. Resumos, p.80

20 - DINIZ, L.S.M.; COSTA, E.O.; FAVA NETTO, C.; DAGLI, M.L.Z. Importância e avaliação do teste de hipersensibilidade do tipo tardio- tuberculina- em mamíferos silvestres mantidos em cativeiro. São Paulo, Brasil. A Hora Veterinária, v.14, n. 82, p. $52-54,1994$.

21 - EMMONS, L. H. Neotropical Rain Forest - A Field Guide. Chicago University of Chicago Press. 1990.

22 - FOWLER, M.E. Zoo and wild animal medicine, 2 ed. Philadelphia, W. B. Saunders, 1986.

23 - FOWLER, M.E. Zoo and wild animal medicine, 3- Current therapy., Philadelphia, W. B. Saunders, 1993.

24 - GRINER, L.A. Pathology of zoo animals Zoological Society, San Diego, 1983, p. 382-7.

25 - INSTRUÇÃO NORMATIVA. Portaria, 1990. IBAMA.

26 - LUTZ, H., HOFMANN, L.R., FEHR, D., LEUTENER, C. HARTMANN, M., OSSENT, P. GROB, M. ELGIZOLI, M., WEILENMANN, P. Reintroduction of wild cat bred in captivity: danger of release of viral infections. Schweiger Archiv für Tierheilkunde, v.138, n. 12, p.579-85, 1996.

27 - Manejo e Conservação da Jaguatirica Leopardus pardalis. In: WORKSHOP DO COMITÊ DO PLANO DE MANEJO E SOCIEDADE DE ZOOLÓGICOS DO BRASIL, 2. Sorocaba, SP, 1993. Anais.

28 - MIKOTA, S.K.; AGUILAR, R.F. Management protocols for animals in captive propagation and reintroduction programmes. Revue Scientifique et Tecnique- Office International des Épizooties, v.15, n.1, p.191-208, 1996. 
29 - MORELLATO, L.P.C. História natural da Serra do Japi. Ecologia e preservação de uma área florestal no sudoeste do Brasil. Campinas, Editora UNICAMP/FAPESP.1992.

30 - NOWAK, R. M. Walker's mammals of the world. Vol. II Baltimore and London, John Hopkins University Press. 1991.

31 - PETERSON, M. K. 1974. Behavior of the margay. In: The World's Cat's. Seatle, Carnivore Research Institute, 1974. 179 p.39-59.

32 - PLANO DE MANEJO DA JAGUATIRICA. Associação Mata Ciliar. Leopardus pardalis. Pedreira-SP. Boletim AMC 1: 3 4,1995 .

33 - PROTOCOLO DE MANEJO INTEGRADO PARA JAGUATIRICA (Leopardus pardalis). Associação Mata Ciliar. Protocolo AMC 1993-1996. Associação Mata Ciliar, Pedreira-SP.

34 - RODRIGUES, A.S.M.; AURICHIO, P. (eds). Protocolo de identificação de pequeno felinos. In: Plano de Manejo da Jaguatirica, 1994. Associação Mata Ciliar, Pedreira-SP.

35 - SCHALLER, G. B. 1983. Mammals and their biomas on a Brasilian ranch. Arquivos de Zoologia do Museu de Zoologia da Universidade de São Paulo, v.31, n.1, p.1-36.

36 - SILVA, J. C. R. Pesquisa de anticorpos anti-Toxoplasma gondii em felídeos silvestres de parques zoológicos do Estado de São Paulo, mediante o emprego do teste de aglutinação do látex. São Paulo, 1997. Dissertação (mestrado). Faculdade de Medicina Veterinária e Zootecnia da Universidade de São Paulo.

37 - SOUZA, E.B.; MORENO, V.R.; OLIVEIRA, E.J.F; ADANIA, C.H.; RAMOS, P.R.R.; MORAES, S.P. Polimorfismo genético- bioquímico das transferrinas em Leopardus pardalis (Mammalia, Felidae). Colloquium, 1998. [no prelo]
38 - THORNBACK, J.; JENKINS, M. The IUCN Mammal Red Data Book. Old Woking, Surrey, UK, The Greshan Press. 1982.

39 - WALLACH J.D., AND W.J. BOEVER. Felines. Diseases of Exotic Animals: Medical and Surgical Management. Philadelphia, W. B. Saunders, 1983. p.612-29.

40 - WIDHOLZER, F.L.; BERGMANN,M.; ZETZ, C. Cuidados especiais para criação de Felis tigrina Elliot, 1977 (Carnivora). In: CONGRESSO DA SOCIEDADE DE ZOOLÓGICOS DO BRASIL. Ribeirão Preto-SP. Arquivos Sociedade de Zoológicos do Brasil, n.3, p.9-11. 1981.

41 - WILDT, D.E.; RALL, W.F.; BALOU, J.; FLESNESS, N.; SEAL, U.S. Establishing genetic resource banks for endangered species. National Research Council Panel on Biodiversity, 1990.

\section{APOIO}

Fundo Nacional do Meio Ambiente, IBAMA, Gerald Lurel Memorial Funds, (Jersey Wildlife Preservation Trust), Sociedade de Zoológicos do Brasil, Lab. Doenças Parasitárias e Lab. Doenças por Bactérias e Fungos da FMVZ-USP

\section{AGRADECIMENTOS}

Aos diretores, veterinários, biólogos e tratadores das Instituições participantes (tabela 1) pela atenção e colaboração.

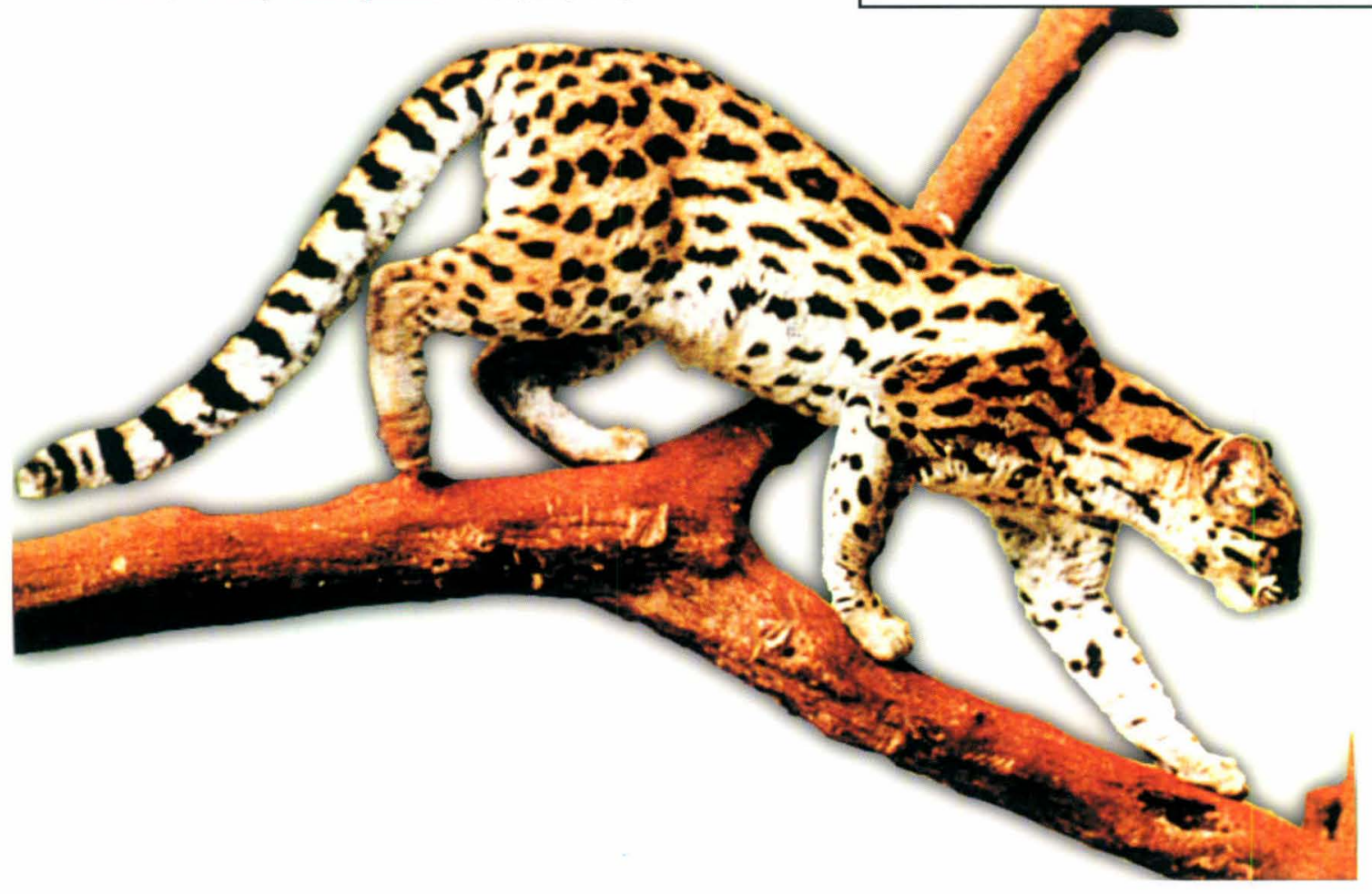

